\section{Seek and Ye Shall Be Fine: Attitudes Toward Political-Perspective Seekers} (II) 8

Gordon Heltzel(D) and Kristin Laurin

Department of Psychology, University of British Columbia
Psychological Science

$1-19$

(C) The Author(s) 2021

(c) (1)

Article reuse guidelines:

sagepub.com/journals-permissions

DOI: $10.1177 / 09567976211011969$

www.psychologicalscience.org/PS

@SAGE

\begin{abstract}
Six preregistered studies $(N=2,421)$ examined how people respond to copartisan political-perspective seekers: political allies who attempt to hear from shared opponents and better understand their views. We found that North American adults and students generally like copartisan seekers (meta-analytic Cohen's $d=0.83$ across 4,231 participants, representing all available data points). People like copartisan perspective seekers because they seem tolerant, cooperative, and rational, but this liking is diminished because seekers seem to validate-and may even adoptopponents' illegitimate views. Participants liked copartisan seekers across a range of different motivations guiding these seekers' actions but, consistent with our theorizing, their liking decreased (though rarely disappeared entirely) when seekers lacked partisan commitments or when they sought especially illegitimate beliefs. Despite evidence of rising political intolerance in recent decades, these findings suggest that people nonetheless celebrate political allies who tolerate and seriously consider their opponents' views.
\end{abstract}

\title{
Keywords
}

political intolerance, intergroup relations, ideology, polarization, perspective seeking, open data, open materials, preregistered

Received 11/18/20; Revision accepted 3/25/21

In 2017, comedian Sarah Silverman launched a talk show, I Love You, America, that had a simple yet unusual premise: Amid antagonistic political polarization, liberal Silverman sought out and interviewed conservative guests about their political perspectives. Perspective seekers such as Silverman develop greater tolerance toward their political opponents and a better understanding of their beliefs (Mutz, 2002), which facilitates cooperation and productive policy discussion (Galinsky et al., 2005; Shi et al., 2019).

Although these outcomes help democracies flourish (McCoy et al., 2018; Mutz, 2002), some modern democracies have become so extremely and antagonistically polarized (Iyengar et al., 2019) that their citizens often take a less productive approach, avoiding and condemning opponents' perspectives (Abramowitz \& Webster, 2018; Frimer et al., 2017). Did Silverman's fellow liberals tolerate her hearing and trying to understand conservatives' beliefs? More broadly, do people approve of ideological allies doing what they themselves often will not: seeking shared opponents' views?

\section{People Might Dislike Political- Perspective Seekers}

Perspective seekers may incur the intolerance that contemporary Americans feel toward political opponents and their views (Finkel et al., 2020; Haidt et al., 2003; Kalmoe \& Mason, 2019). Now more than at any time in recorded history, Americans find their opponents intolerable, immoral, and unreasonable (Pew Research Center, 2019). They also feel that their own political beliefs are more legitimate-morally and objectively rightthan their opponents' beliefs (Schwalbe et al., 2020), which they find deeply upsetting (Dorison et al., 2019) and will even forgo payment to avoid hearing (Frimer et al., 2017).

\footnotetext{
Corresponding Author:

Gordon Heltzel, University of British Columbia, Department of Psychology

Email: gheltzel@psych.ubc.ca
} 
If this intergroup animosity also occurs in intragroup contexts, this might lead people to rebuke political allies who engage in good faith with unreasonable, immoral opponents. Indeed, some recent studies have found that people dislike copartisan politicians who compromise with opponents (Ryan, 2017) and reject those who empathize with proponents of illegitimate views (Wang \& Todd, 2020). Perspective seekers' behavior may elicit similar reactions: It may signal that the seeker is open to compromise or even to changing their mind, betraying the partisan cause. At the very least, such behavior implies that opponents' abhorrent views are legitimate enough that they can be understood.

\section{People Might Like Copartisan Political- Perspective Seekers}

Different recent studies suggest that rampant intolerance between political groups may not transfer to intragroup contexts. People like copartisans who show respect and civility toward opponents (Druckman et al., 2019; Frimer \& Skitka, 2018), hinting that they might also like allies who seek opposing perspectives. Indeed, seeking other views implies tolerance toward dissimilar people and ideas (Mutz, 2002), a rational approach to evidence and arguments (Golman et al., 2017), and cooperativeness toward finding common ground (Galinsky et al., 2005). These three characteristics generate liking and admiration, especially in Western democracies (W. Brown, 2009; Fehr \& Fischbacher, 2004; Fiske et al., 2007; Norenzayan et al., 2002; Ståhl et al., 2016).

\section{Dual Mechanisms?}

Although people are themselves intolerant of their political opponents, existing work provides mixed evidence regarding their feelings toward allies who tolerate shared opponents. The reception to I Love You, America reflects this apparent paradox: Despite critical acclaim and multiple Emmy nominations, it received mediocre viewer ratings and lasted only two seasons. We posit that, taken together, these mixed findings hint at divergent but coexisting psychological mechanisms: Seekers embody admirable traits yet simultaneously alarm their allies by seeming to validate and potentially adopt opponents' illegitimate views. We tested the relative strength of these mechanisms to establish whether people generally like or dislike perspective seekers.

\section{Individual Differences}

We also considered perceivers' own characteristics. Those who are most intolerant of their political opponents may similarly be most alarmed by allies who seek

\section{Statement of Relevance}

Political animosity has escalated in modern democracies, especially America. In response, some leaders and scholars have called for citizens to understand and empathize with opponents. But if you tried to genuinely understand where your political opponents are coming from, would your political allies commend your tolerant and rational approach or instead condemn it, worried that you are validating illegitimate views and might even abandon the shared cause? We found that Americans and Canadians preferred political allies who seek out rather than avoid shared opponents' views. Liberals and conservatives, as well as moderates and extremists, all showed this preference, though it was smaller among extremists. The preference was also weaker when seekers seemed at risk of changing their minds or when they sought especially extreme opponents' views. Although past research shows that people themselves tend to be intolerant of political opponents, it seems that they prefer others who can overcome these political divides.

those opponents' perspectives. Debates rage over who is most politically intolerant: conservatives (Ganzach \& Schul, 2021), ideological extremists (Crawford, 2014), or people whose political beliefs stem from moral concerns (Skitka, 2010). Our studies contributed to these debates, testing whether these three groups' attitudes toward political-perspective seekers differ from their respective counterparts'.

\section{Overview of Studies}

Studies 1a, 1b, and 1c established people's attitudes toward political allies who seek shared opponents' beliefs and tested for two divergent mechanisms. We then report an internal meta-analysis including the studies in our file drawer (10 studies, all of which support findings reported here), testing whether these attitudes vary with participants' political beliefs. Studies 2 through 4 tested potential moderators, examining whether observers' attitudes change with targets' motivation for seeking (Study 2), their commitment to observers' own views (Study 3), or the illegitimacy of the views they seek (Study 4). We focused on the American political context because our theorizing draws on empirical findings from America and is most relevant in polarized democracies such as America, where citizens admire tolerance and rationality yet find their opponents' beliefs illegitimate. 
In most of the studies reported in this article and in the Supplemental Material available online, we recruited American adults because our theorizing best applies to this population. Two studies recruited Canadian participants (Study 1c recruited students and Study S8 in the Supplemental Material recruited adults quotamatched to the population's income and education levels); we further consider generalizability in the General Discussion. Fifteen of the 16 studies were preregistered; all preregistrations describe power analyses guiding our sample sizes, detailed methods, and analysis plans. Exclusion criteria were preregistered in all studies to ensure data quality (e.g., Chmielewski \& Kucker, 2020); the Supplemental Material reports each study's (virtually identical) results, including those for all participants with no exclusions. All data and materials are available on OSF (see https://osf.io/3zwxc/ and https://osf.io /uksdf/, respectively). For all studies, we report all conditions, data exclusions, and preregistered analyses. All analyses for all studies were run in RStudio (Version 1.2.5001; RStudio Team, 2019) and were preregistered unless otherwise noted. For each Mechanical Turk study, participants who had completed one of our previous studies were not allowed to participate.

\section{Studies 1a, 1b, and 1c}

Participants reacted to copartisan targets who either sought or avoided opponents' perspectives. Study 1a tested our theorized divergent mechanisms, and Study $1 \mathrm{~b}$ included a baseline copartisan target. These studies used different participant pools and political divisions and measured online attitudes and in-lab behavior.

\section{Study 1a: metbod}

Overview. For Study 1a's preregistration, see https://osf .io/mjt7u. In this within-subjects study, participants read about two targets who were both copartisans (i.e., shared the participants' view on a particular issue). One target sought opponents' views on that issue; the other avoided them. Participants reported attitudes toward each target and also reported perceptions of the targets' attributes corresponding to our divergent mechanisms.

Participants. We recruited 251 American participants from Prolific Academic. We excluded 17 participants who failed an instructional attention check (a block of instruction text asking them to type a specific phrase into a text box) and one who self-reported data that were too low in quality for us to use, leaving 233 participants ( $52 \%$ female; mean age $=33.15$ years). They tended toward liberalism $(M=2.91, S D=1.60$, significantly below the scale midpoint of 4$), t(232)=-10.36, p<.001 .^{1}$
Issue selection and copartisan assignment. Participants read about four hotly debated issues-affirmative action, climate change, immigration, and welfare-and chose, for each issue, which of two stances they preferred. For example, they read that immigration "concerns how the government regulates the movement of individuals from foreign countries into the United States of America, especially those that intend to work and stay in the country." The two stances they could choose from were "support tougher immigration policies" and "oppose tougher immigration policies."

Participants then read a vignette describing Individual $\mathrm{A}$ and Individual $\mathrm{B}$, who shared their beliefs about one of the four issues selected at random. For example, a participant supporting tougher immigration policies might read this:

Both Individual A and Individual B support tougher immigration policies and believe that immigrants can have negative social and economic effects on the country. In addition, both Individual $\mathrm{A}$ and Individual $\mathrm{B}$ often hear about immigration from the perspective of those who have similar views, such as TV news anchors and authors who argue in favor of tougher immigration policies.

Target manipulation. The vignette then described the perspective seeker and avoider:

However, Individual A also sometimes watches news anchors who oppose tougher immigration policies, and occasionally reads articles by authors with these views. In contrast, Individual B hardly ever watches news anchors who oppose tougher immigration policies, and rarely reads articles by authors with these views.

Primary measures. Our dependent variable was composed of three attitude measures toward each target. Our divergent mediators included five attributes rated for each target. These two sets of measures were counterbalanced.

Attitudes. Participants first completed a feeling thermometer for each target, using a sliding scale from 0 to 100 to respond to the prompt:

Please rate your feelings towards the individuals you read about in the vignettes using the labels provided above. Ratings above 50 mean you feel favorable and warm toward the person, with 100 being the most positive response; ratings below 50 mean you don't feel favorable toward the person and that you don't care too much for that person, with 0 being the most negative rating. 

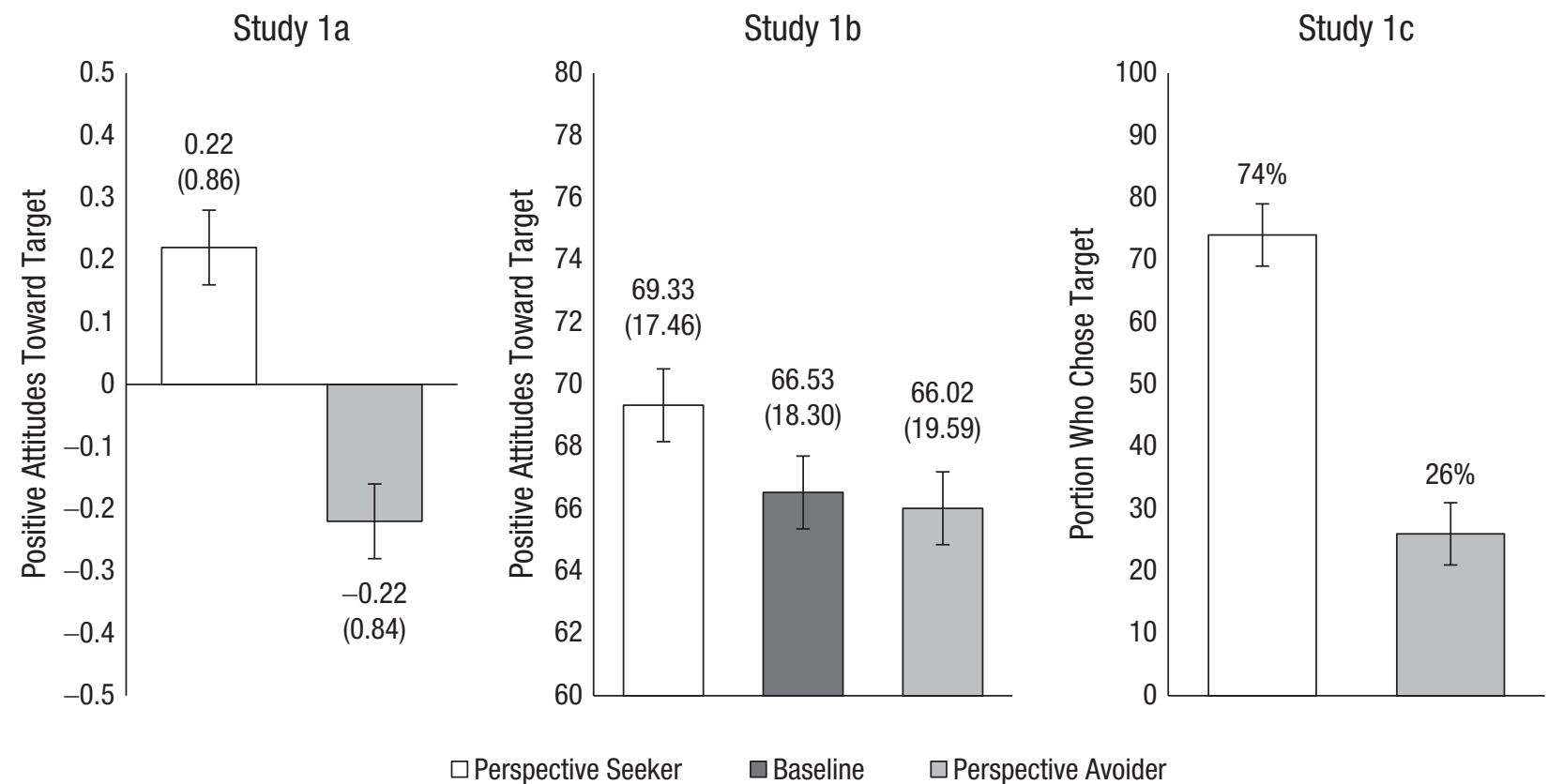

Fig. 1. Attitudes toward targets in Studies 1a, 1b, and 1c. For Studies 1a and 1b, mean ratings are shown for each target type. For Study 1c, the percentage of participants who preferred to work with each target is shown. Attitudes in Study 1a were standardized. For the self-reported-scale measures used in Studies 1a and 1b, standard deviations appear in parentheses. Error bars represent standard errors.

Second, again for each target, participants rated four statements $(\alpha=.94)$ beginning with the stem, "I would be happy to have [Individual $\mathrm{A} / \mathrm{B}$ ] as ...." and ending with "a friend," "the teacher of my children," "governor of my state," or "President of the United States" (adapted from Skitka et al., 2005). Responses were made on a scale ranging from 1 (strongly disagree) to 7 (strongly agree).

Third, again for each target, participants reported whether they felt two positive emotions ("proud of" and "respect for") and four negative emotions ("angry at," "disgusted at," "look down on," and "ashamed of"; all reverse scored). Responses were made on a scale ranging from 1 (strongly disagree) to 7 (strongly agree; $\alpha=.89$ ).

Following our preregistration, we standardized and then averaged these measures into our dependent variable $(\alpha=.85)$.

Mediators. Participants rated each target on five attributes. They read the stem, "Please consider Individual $[\mathrm{A} / \mathrm{B}]$ 's behavior. By behaving this way, Individual $[\mathrm{A} / \mathrm{B}]$ is ..." and then, for each attribute, responded on a scale ranging from 1 (not at all) to 7 (very much). Three of these attributes were the valued traits we thought participants would ascribe to seekers: "tolerant of dissimilar people," "cooperative," and "rational, logical" ( $\alpha=$ $.90)$. The other two reflected concerns with validating or adopting opponents' views: "implying anti-immigration action views could be right" and "open to changing her mind about immigration" ( $\alpha=.71)$. Exploratory analyses for each attribute separately are reported in the Supplemental Material; each accounted for an independent indirect effect in the expected direction, and all but one achieved full or marginal significance. ${ }^{2}$

\section{Study 1a: results}

Overall preferences. First, we ran a model predicting participants' attitudes from target type (seeker coded 1, avoider coded 0) and with a random intercept for participant. Participants preferred the target who sought rather than avoided opposing political perspectives, $b=0.44$, $S E=0.067,95 \%$ confidence interval $(\mathrm{CI})=[0.30,0.57]$, $t(232)=6.48, p<.001, d=0.51$ (see Fig. 1$)$.

Divergent mechanisms. Next, we tested a parallel multilevel mediation model to determine whether the two sets of attributes (valued traits and concerns about validating and adopting opponents' views) independently accounted for participants' preference for seekers (lavaan Version 0.6-5; Rosseel, 2012). As expected, the two composites accounted for opposing indirect effects (see Fig. 2). On the one hand, there was a relatively large positive effect through participants' view of the seeker as tolerant, cooperative, and rational, which explains why 


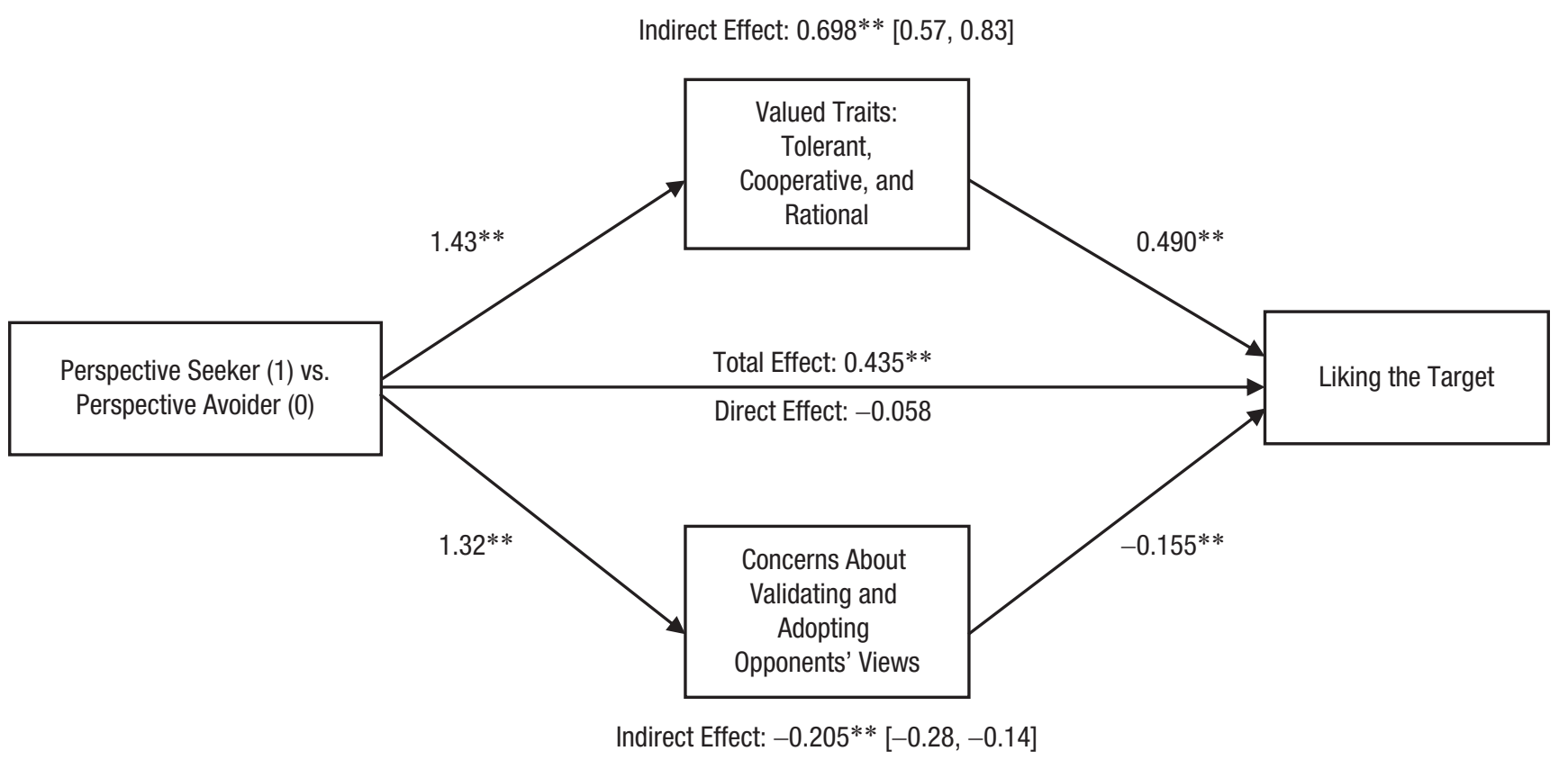

Fig. 2. Results of mediation analyses in Study 1a: influence of participants' preferred stance on their liking for the target, as mediated by valued traits (top) and concerns about validating and adopting opponents' views (bottom). Unstandardized coefficients are shown. Values in brackets are 95\% confidence intervals. Asterisks indicate significant paths $(p<.001)$.

they preferred this target. On the other hand, there was a relatively small negative indirect effect through participants' concerns that the seeker was validating and could adopt opponents' views, and these concerns suppressed their overall preference. After both mechanisms were accounted for, no direct effect remained. Sensitivity analyses, reported in the Supplemental Material, suggest that this model is relatively robust to possible unmeasured confounds. Moreover, Study S10, also reported in the Supplemental Material, used a pilot sample and a preregistered sample that each replicated this exact pattern and confirmed that these mechanisms are particularly relevant for perspective seeking on political issues, as opposed to other concerns. Still, mediation analyses cannot speak to the causal role of any mediator; in that sense, they provide merely correlational information. ${ }^{3}$

\section{Study 1b: metbod}

Overview. In Study 1b (https://osf.io/6s8gc), we aimed to replicate the preference for seekers using a different political division (over broad ideological identities rather than specific policy issues) and different stimuli that depicted the targets' behavior more concretely (the time they spent watching news from ideologically biased sources rather than their general approach to news). Study $1 \mathrm{~b}$ also included a control target to test whether, relative to typical copartisans, people like seekers, dislike avoiders, or both.
Participants. We recruited 304 American participants from Amazon's Mechanical Turk. Following our preregistration, we excluded 47 participants who failed an attention check, eight who self-reported their data were low quality (as in Study 1a), eight who failed an Englishcomprehension check (identifying the referent of a pronoun in a complex sentence), and 30 who responded incoherently to an open-ended exploratory question at the end of the survey. These exclusions overlapped, leaving 233 participants ( $55 \%$ female; mean age $=34.80$ years). They tended toward liberalism $(M=3.30, S D=$ 1.49 , just below the scale midpoint of 3.5$), t(232)=$ $-2.04, p=.042$.

Copartisan assignment. Participants first reported their demographic information, including their political orientation measured on a 6-point scale with no midpoint. This forced participants to identify as some degree of either liberal or conservative.

On each of the next three separate survey pages, participants read a profile describing a copartisan target who had responded to a public-opinion poll. Each profile listed the target's political ideology as liberal or conservative (matched to participants'), along with filler information (e.g., targets' age and hobbies, randomized across targets).

Target manipulation. Each profile also contained a bar graph of the target's average weekly consumption of 

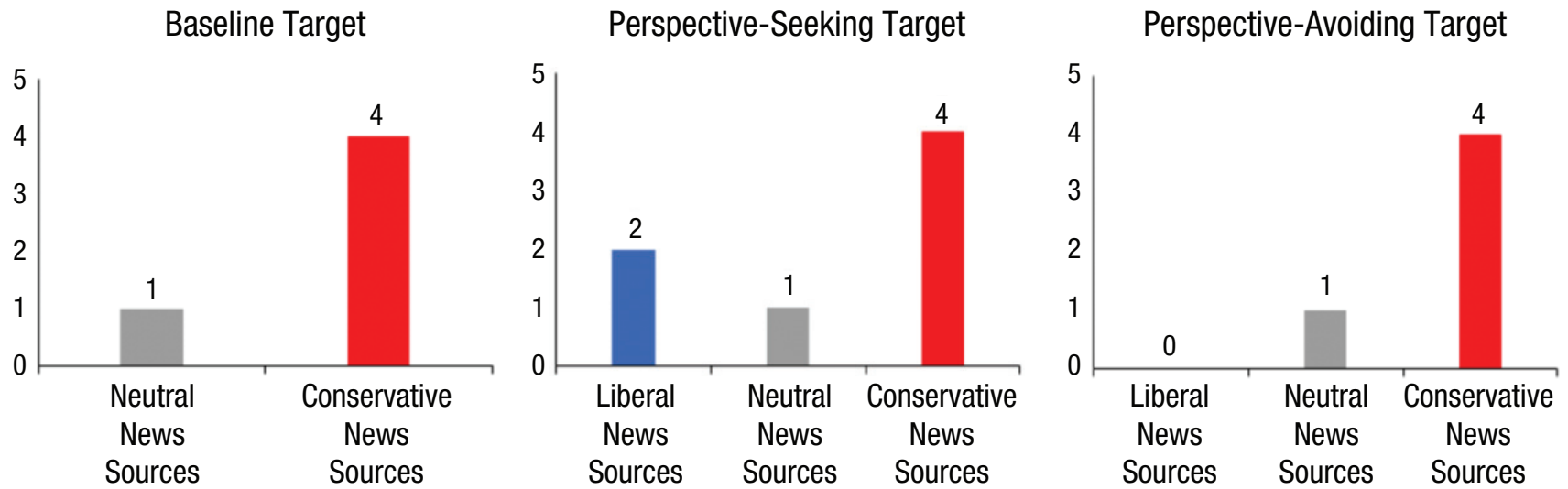

Fig. 3. Example stimuli graphs seen by conservative participants in Study $1 \mathrm{~b}$. The $y$-axis depicts how many hours per week the target watched news from sources listed on the $x$-axis.

politicized news sources (see Fig. 3). Participants always saw the baseline target first; their graph showed data for two categories of news sources: (a) sources ideologically consistent with the participant's (and the target's own) leanings and (b) ideologically neutral sources. The baseline target spent $4 \mathrm{hr}$ per week viewing ideologically consistent news and $2 \mathrm{hr}$ per week viewing ideologically neutral news. These viewing times were identical to the experimental targets', described below. Crucially, though, the baseline target's graph omitted a third category: sources that ideologically clashed with participants' leanings. Thus, participants could make whatever assumptions they wanted to about their political allies' typical consumption of opposing news sources. (Study S7 used a similar paradigm but explicitly stated that, because of technical errors, this target had missing data for that category. The results of Study S7 were virtually identical to those of Study 1b; see the Supplemental Material for Study S7.)

The next two targets-the seeker and avoiderappeared in random order. Their graphs showed the same two categories and viewing hours as the baseline target's but included one extra category: sources ideologically opposed to the participant's (and their own) leanings. The seeker spent $2 \mathrm{hr}$ per week viewing these sources, and the avoider spent 0 hr (Fig. 3).

Measures. After seeing each target but before moving on to the next, participants reported their attitudes using the feeling-thermometer measure used in Study 1a. ${ }^{4}$

\section{Study 1b: results}

We ran a multilevel model predicting feeling-thermometer ratings from target type (perspective seeker, avoider, and baseline; dummy coded with seeker as reference target) and with a random intercept for participant and covariates for the target's age and hobbies (see Fig. 1). As in Study 1a, participants liked perspective seekers more than perspective avoiders, $b=-3.31, S E=1.19,95 \% \mathrm{CI}=[-5.64,-0.99], p=.005$, $d=0.18$; they also liked them more than baseline copartisans, $b=-2.81, S E=1.19,95 \% \mathrm{CI}=[-5.13,-0.48]$, $p=.018, d=0.16$. A follow-up analysis found no difference between the perspective-avoiding and baseline targets, $b=0.51, S E=1.19,95 \% \mathrm{CI}=[-1.82,2.83], p=$ $.670, d=0.03$, suggesting that people's preference is driven by liking for seekers.

\section{Study 1c: method}

Overview. Hypothetical responses do not always extend to real situations (Liberman \& Trope, 2008), so Study 1c (https:// osf.io/hnb5s) measured behavior in live interactions. Participants met copartisan confederates (one self-described perspective seeker and one self-described perspective avoider) and chose whom to work with on a task.

Participants and copartisan assignment. One hundred seventy-eight undergraduate participants from a Canadian university human-subject pool completed a screener survey to determine their eligibility. Eligibility was based on their familiarity with and position on Canada's carbon-tax policy, which was the key political issue in this study. It was hotly contested in Canadian politics at the time of the study, so we believed it would be comparable with the issues used for our American samples (we confirmed this belief in Study S8).

Eligible participants had to have lived in Canada since at least age 14 so they would be familiar with Canadian politics. Of the initial 178 participants, 131 met this criterion. Eligible participants also had to support Canada's carbon-tax policy: They would meet copartisan confederates, and we worried that participants who opposed the carbon tax, a minority on campus, would become suspicious if both ostensible other participants happened to share their unpopular view. Indeed, 106 
(81\%) of the remaining participants supported the carbon tax, and all completed our study.

Following our preregistration, we excluded data from five participants who were suspicious and five who experienced technical issues (familiarity with confederates, confederates straying from script, computer issues). No participant met our third exclusion criterion (failing to recall that the confederates had mentioned the carbon tax). This left 96 participants ( $79 \%$ women, $1 \%$ nonbinary; mean age $=19.95$ years). They tended toward liberalism $(M=3.27, S D=1.04$, significantly below the scale midpoint of 4$), t(94)=-6.83, p<.001$ (one participant did not report ideology).

Procedure. Sessions featured either one or two real participants along with two confederates posing as other participants. We matched confederate pairs for gender and ethnicity and, within each pair, counterbalanced which research assistant played which confederate role.

An experimenter greeted participants and sat them at a table with the confederates next to each other. The experimenter gave each participant a sheet of paper, asked them to write a brief introduction to read to the others, and suggested they mention a topic they care about. The confederates' scripts were printed in light font on their sheets; they traced over their scripts while the real participants wrote their introductions.

The experimenter then had all group members introduce themselves and suggested that everyone take notes on each other's introductions, to help them remember details for later in the study. The participants introduced themselves first, followed by the confederates. When the perspective-seeking confederate spoke, she said the following:

Alright-Hi guys, my name is [confederate stated name clearly]. I'm a 2nd year psych major, and one thing that I really care about is the environment. I think we should take action to stop climate change and I think taxing people and businesses who use a lot of carbon is a great way to reduce emissions. It's crazy to me that there are people who oppose the carbon tax, but I've been trying to take their perspective, and to understand why they feel that way. Anyway, that's all I had written.

To ensure any preference for seekers was not merely due to a preference for civility and politeness (Frimer \& Skitka, 2018), we included cues of incivility in the perspective-seeking confederate's script (P. Brown \& Levinson, 1987), such as imposing language (i.e., "take action") and mild insults ("It's crazy to me").

The perspective-avoiding confederate spoke last, saying the following:
Okay-hi everyone, my name is [confederate stated name clearly] and I'm a 3rd year psych major. And it's funny you mentioned the environment, because I wrote down the same thing. I think caring for the environment is really important. And I agree with you that the carbon tax is a great way to try to stop climate change. But I'm not sure that we feel the same about people who don't like the carbon tax. I guess I really don't understand their perspective either, but honestly, I just don't think taking their perspective is the answer here [confederate shrugs]. But yeah, that's all I've got.

For the reason described above, the perspectiveavoiding confederate's script included cues of civility such as belonging and acceptance (e.g., "I wrote the same thing," "I agree with you") as well as hedging language (e.g., "I'm not sure," "I guess").

Following these introductions, participants took their notes to a private cubicle and completed an online survey. They reported the other participants' names and completed demographic measures and filler items before proceeding to the dependent measure.

Measures. Participants read the following instructions: "For this task, you will work with a partner. Please rank the other participants that are taking part in today's study in the order of who you would like to work with most."

They then saw the names they had previously entered and entered a number next to each one, with " 1 " denoting the most preferred partner and "2" (or "3," in four-person sessions) denoting the least. Because of this difference between three- and four-person sessions, we coded participants' choice as 1 if they ranked the seeker higher than the avoider and 0 if they did the opposite.

Next, participants rated how well several traits described the other participants, including "openminded," as a manipulation check, and "polite," to control for civility (Frimer \& Skitka, 2018). They then completed suspicion and attention checks, read a debriefing, and received course credit. ${ }^{5}$

\section{Study 1c: results}

Our manipulation was successful: Participants rated the perspective-seeking confederate $(M=5.53, S D=1.49)$ as more open-minded than the perspective-avoiding confederate $(M=4.65, S D=1.54), t(95)=4.36, p<.001$, $d=0.58$. This analysis was not preregistered.

Overall, 71 of the 96 participants (74\%) preferred to work with the perspective-seeking confederate (see Fig. 1), compared with only 25 (26\%) preferring the avoider, $\chi^{2}(1, N=96)=22.04, p<.001, d=1.09$. For our 
preregistered test, a multilevel binomial logistic model predicted partner choice from two planned covariates: the perceived difference in politeness between confederates (perceived politeness of seeker minus avoider) and a random intercept for the identity of the seeker confederate (to account for actor-specific variance). This model's intercept, $b=1.03, S E=0.241, z(95)=4.26$, $p<.001$, confirmed the pattern in the raw data: Participants were almost three times more likely to choose the seeker for their partner, odds ratio $(O R)=2.79,95 \%$ $\mathrm{CI}=[1.74,4.48]$. This held when analyses controlled for politeness (which predicted partner choice; $p=.029$ ), so participants' preference for seekers was not due to preferring polite, civil partners.

\section{Discussion}

Observers liked copartisan political-perspective seekers better than political-perspective avoiders and neutral copartisans. Seekers seemed tolerant, cooperative, and reasonable, and these perceptions more than counteracted seekers' seeming to validate, and potentially adopt, opponents' beliefs. People's preferences had behavioral consequences in a live social interaction, in which they chose to spend time with a seeker over an avoider.

\section{Internal Meta-Analysis}

We pause here to emphasize the robustness of people's preference for seekers. Indeed, this preference emerged in every study conducted in the present research-the three already reported, the three remaining, and the 10 remaining studies we conducted in this line of research (described in the Supplemental Material). To demonstrate this point empirically, and to test pressing questions about whether people's preference varies with characteristics of their political beliefs, we conducted a metaanalysis using all available data points. We present the results of this meta-analysis before describing Studies 2 through 4 , which tested theoretically derived moderators of the effect.

\section{Metbod}

Inclusion criteria. We included all data testing our theoretical account-that is, all ratings of copartisan political seekers or avoiders (i.e., excluding baseline copartisans and some participants from Studies 3, S6, and S10 who saw targets who were not political copartisans; see the Supplemental Material for Studies S6 and S10). We also excluded data from Study 1c because its binary dependent variable was incompatible with the continuous dependent variables used elsewhere. This left a meta-analytic sample of 4,231 participants, from both within-subjects studies (Studies 1a-1c, 4, S1-S7, and S10) and between-subjects studies (Studies 2, 3, S8, and S9) using stimuli similar to those in either Study 1a or 1b (see the Supplemental Material for Studies S1-S10). Table 1 shows each study as well as the $p$ value and effect size ( $d$ ) obtained in the comparison of seekers with avoiders; for the supplemental studies, the reason why we chose to omit the study from the main article is given in the table note.

Dependent measure. The dependent variable in most studies was the attitude composite (feeling thermometer, social proximity, and emotions, standardized and then averaged within studies). Studies $1 \mathrm{~b}$ and S7 used only the thermometer, which we standardized; Study S10 used only the thermometer and emotion measures, which we standardized and averaged.

\section{Characteristics of participants' beliefs.}

Political ideology. Some past work has found that ideological conservatives are more intolerant of their opponents (Ganzach \& Schul, 2021). Participants reported their ideology in each study, responding to the question, "In general, to what extent do you consider yourself to be liberal or conservative?" Most studies used a scale ranging from 1 (extremely liberal) to 4 (moderate) to 7 (extremely conservative); Studies 1b and S7 used 6-point scales with no moderate midpoint, and S8 used a 10-point scale ranging from 1 (left) to 10 (right). We used these ideological labels in Canadian samples as well because they are well known in this population and are distinguished from the capital-L Liberal Party and the capital-C Conservative Party that vie for leadership of the country. These labels are also commonly used by researchers studying political topics in Canadian samples (e.g., Pennycook et al., 2021).

To make ideology comparable across studies, and because our samples skewed liberal (making their means less-than-ideal center points from which to estimate extremity), we used the proportion of maximum possible (POMP) approach (Cohen et al., 1999), assigning each participant a value between 0 and 1, representing the proportion at which their score falls along the scale they used. For instance, on a 7-point scale, a participant who selected 5 would receive a POMP score of .83 , because 5 is $83 \%$ of the way to 7 , starting from 1 .

Political extremity. Other past work has found that political extremists are more intolerant of their opponents (Crawford, 2014; Ganzach \& Schul, 2021). We indexed ideological extremity as the absolute value of the distance of each participant's POMP score from the midpoint of .5 .

Moral conviction. Yet other work has found that people bearing moralized political beliefs are especially intolerant of their opponents (Skitka, 2010). Two studies (Studies S1 and S2 in the Supplemental Material) included a measure of moral conviction-"How much are your 
Table 1. Results of the Comparison of Perspective Seekers and Perspective Avoiders in Each Study

\begin{tabular}{|c|c|c|c|c|}
\hline Study & $p$ & $d$ & $N$ & Additional questions tested \\
\hline Study 1a & $<.001$ & 0.51 & 233 & Are there two opposing mechanisms? \\
\hline Study $1 b$ & .005 & 0.18 & 233 & What about baseline copartisans? \\
\hline Study 2 & $<.001$ & 0.51 & 829 & $\begin{array}{l}\text { Do people prefer seekers regardless of their motive for } \\
\text { seeking? }\end{array}$ \\
\hline Study 3 & $<.001$ & 0.64 & 194 & $\begin{array}{l}\text { Do people prefer seekers even when the seekers are less } \\
\text { committed? }\end{array}$ \\
\hline Study 4 & $<.001$ & 0.57 & 231 & $\begin{array}{l}\text { Do people prefer seekers even when they consider } \\
\text { seekers' views very illegitimate? }\end{array}$ \\
\hline Study S1 & $<.001$ & 1.22 & 366 & \\
\hline Study S2 & $<.001$ & 1.37 & 261 & \\
\hline Study S3 & $<.001$ & 1.23 & 259 & \\
\hline Study S4 & $<.001$ & 1.39 & 244 & What traits do people attribute to seekers and avoiders? \\
\hline Study S5 & $<.001$ & 1.56 & 233 & $\begin{array}{l}\text { Is the preference for seekers mediated by warmth } \\
\text { perceptions? }\end{array}$ \\
\hline Study S6 & $<.001$ & 1.36 & 211 & $\begin{array}{l}\text { Does speaking order explain the preference for seeking? } \\
\text { Do people prefer out-group seekers or out-group } \\
\text { avoiders? }\end{array}$ \\
\hline Study S7 & .007 & 0.14 & 268 & $\begin{array}{l}\text { Do people prefer seekers when stimuli features specific, } \\
\text { ideologically biased news channels? }\end{array}$ \\
\hline Study S8 & $<.001$ & 1.34 & 168 & $\begin{array}{l}\text { Does the preference for seekers emerge among } \\
\text { Canadians for the carbon-tax issue? }\end{array}$ \\
\hline Study S9 & $<.001$ & 0.74 & 256 & $\begin{array}{l}\text { Do people still prefer seekers driven by yet a different set } \\
\text { of motives? }\end{array}$ \\
\hline Study S10 (pilot) & $<.001$ & 1.00 & 99 & $\begin{array}{l}\text { How specific are these effects to political-perspective } \\
\text { seeking? }\end{array}$ \\
\hline $\begin{array}{l}\text { Study S10 } \\
\quad \text { (preregistered) }\end{array}$ & $<.001$ & 0.96 & 146 & $\begin{array}{l}\text { How specific are these effects to political-perspective } \\
\text { seeking? }\end{array}$ \\
\hline
\end{tabular}

Note: Studies S1 to S6 were not included in the main text because their design replicated that of Study 1a without key mediators. Studies S7 and S9 were not included because their designs replicated those of Studies $1 \mathrm{~b}$ and 2, respectively, with a smaller sample. Study S8 was not reported because it was a less ecologically valid version of Study 1c. Neither version of Study S10 was included because the study's design replicated that of Study 1a.

feelings about [e.g., abortion] connected to your core moral beliefs or convictions?"-rated on a scale from 1 (none at all) to 7 (very much).

Alternative indices of ideology and extremity. For robustness, we operationalized extremity and ideology in additional ways. For one, we standardized self-reported political orientation within studies to represent ideology and then squared that value for a quadratic term to represent extremity. For another, in addition to the symbolic measures described thus far (i.e., identification with ideological labels), some studies included operational measures (support for policy positions). For ideology, this measure was participants' stance on policy debates (as in Study 1a); for extremity, it was how strongly they held those stances $(1=$ not at all, $7=$ extremely $)$.

\section{Results}

Overall effect sizes. Before testing for moderation, we determined the overall effect size. A multilevel model predicting attitudes from target type (seeker coded 1, avoider coded 0) and random intercepts nesting participant within study found a large preference for perspective seekers over perspective avoiders, $b=0.70, S E=0.019$, $t(3807)=36.19, p<.001, d=0.83,95 \% \mathrm{CI}=[0.78,0.88]$.

Next, we examined studies with a baseline copartisan target, this time including all three target types (Studies 1b, 2, S7, and S9; total $n=1,863$ ). A multilevel model predicting attitudes from dummy-coded target (baseline as the reference group) and random intercepts nesting participant within study found that people preferred seekers over baseline copartisans and preferred these baseline copartisans over avoiders (see Table 2).

Moderation by characteristics of participants' beliefs. We next tested whether our effects differed by participants' conservatism, extremism, and/or moral conviction (see Table 3). For each potential moderator, we tested a multilevel model predicting attitudes from target (seeker coded 1, avoider coded 0), moderator (centered), their interaction, and a random intercept 
Table 2. Results From the Model Comparing Participants' Attitudes Toward Perspective Seekers, Perspective Avoiders, and Baseline Copartisan Targets in the Internal Meta-Analysis of Studies 1b, 2, S7, and S9

\begin{tabular}{lcccccc}
\hline Comparison & $b$ & $S E$ & $t$ & $d f$ & $p$ & $d$ \\
\hline $\begin{array}{l}\text { Seeker versus } \\
\text { baseline }\end{array}$ & 0.173 & 0.034 & 5.03 & 1778 & $<.001$ & 0.19 \\
$\begin{array}{l}\text { Avoider versus } \\
\text { baseline }\end{array}$ & -0.101 & 0.034 & -2.94 & 1777 & .003 & -0.17 \\
\hline
\end{tabular}

nesting participant within study (our sample size for testing moralization was much smaller; $n=625$ ). We then estimated the effect of target at the moderator's minimum (e.g., among the most liberal participants with POMP ideology scores of 0 , the most moderate participants with POMP extremity scores of 0 , and participants with the lowest moralization scores [1]) and at the moderator's maximum (e.g., among the most conservative participants with POMP ideology scores of 1 , the most extreme participants with POMP extremity scores of .5, and participants with the highest moralization scores [7]). For operational measures, we used the same approach. For standardized measures, we tested both moderators in a single model (because one was the square of the other); moreover, we tested the simple slopes at \pm 2 (i.e., $\pm 2 S D$ ) on standardized ideology and at 0 (the most moderate score) and 4 (the square of \pm 2 ) on extremity.

Across these analyses, we found the clearest evidence that the preference for seekers varied with participants' extremism. At the same time, our data may characterize extremists as less tolerant than moderates but hardly as intolerant: Even maximally extreme participants-along with the most conservative and those with the highest moral convictions-displayed a reliable preference for political allies who seek rather than avoid their opponents' views (all ps $<.003$ ). Having established that this preference is robust across participant characteristics, in Studies 2 through 4, we aimed to test whether it weakens in specific, theoretically derived circumstances.

\section{Study 2}

Study 2 tested circumstances that might weaken the preference for seekers. First, we wondered whether participants preferred seekers only because they attributed a perfect motivation to them: to (cooperatively, tolerantly, rationally) hear out opponents while staying committed to their beliefs. Study 2 (https://osf.io/ dvbhu) tested whether this preference persisted when seekers held common and consequential (Pierce et al., 2013) yet imperfect motives: wanting to compromise

Table 3. Results From the Model Testing Ideological Orientation and Extremity as Moderators of Participants' Attitudes Toward Targets (Perspective Seeking vs. Perspective Avoiding) in the Internal Meta-Analysis of Studies

\begin{tabular}{|c|c|c|c|c|}
\hline \multirow[b]{2}{*}{ Variable } & \multicolumn{2}{|c|}{$\begin{array}{c}\text { Interaction with } \\
\text { target }\end{array}$} & \multicolumn{2}{|c|}{$\begin{array}{c}\text { Estimated } b \text { of target } \\
\text { at extremes }\end{array}$} \\
\hline & $b$ & $S E$ & Minimum & Maximum \\
\hline \multicolumn{5}{|c|}{ Ideology measures } \\
\hline POMP ideological orientation ${ }^{a}$ & -0.080 & 0.069 & $0.74^{* * *}$ & $0.66^{\text {*** }}$ \\
\hline Standardized orientation $^{\mathrm{a}}$ & 0.007 & 0.020 & $0.69 * *$ & $0.72^{* * *}$ \\
\hline Issue stance ${ }^{a}$ & $-0.121^{*}$ & 0.046 & $0.91 * *$ & 0.79 *** \\
\hline \multicolumn{5}{|c|}{ Extremity measures } \\
\hline POMP ideological extremity ${ }^{\mathrm{b}}$ & $-1.023^{* * *}$ & 0.115 & $0.95^{\text {*** }}$ & $0.44^{* * *}$ \\
\hline Squared standardized orientation ${ }^{\mathrm{b}}$ & $-0.178^{* * *}$ & 0.018 & $0.88^{* * *}$ & $0.17^{*}$ \\
\hline Issue-attitude strength ${ }^{\mathrm{b}}$ & $-0.093^{* *}$ & 0.014 & $1.29^{* * *}$ & $0.68^{* * *}$ \\
\hline Moral conviction $^{c}$ & -0.001 & 0.026 & $0.94^{* * *}$ & $0.94^{* * *}$ \\
\hline
\end{tabular}

Note: Studies 1a, 4, and S10 were excluded from meta-analytic tests of issue stance and issueattitude strength because they did not measure issue-attitude strength. POMP $=$ proportion of maximum possible.

${ }^{a}$ Higher scores on this measure indicate that participants were more conservative. ${ }^{b}$ Higher scores on this measure indicate that participants were more extremist. 'Higher scores on this measure indicate that participants had greater moral conviction. $* p<.01 .{ }^{* *} p<.001$. 
Table 4. Wording for All Five Conditions in Study 2, Using the Example of a Pro-Choice Participant in the Abortion Condition

\begin{tabular}{|c|c|c|c|}
\hline \multirow[b]{2}{*}{ Target } & \multirow[b]{2}{*}{ Description of target } & \multicolumn{2}{|c|}{ Target's motive } \\
\hline & & Cooperative & Competitive \\
\hline $\begin{array}{l}\text { Perspective } \\
\text { seeker }\end{array}$ & $\begin{array}{l}\text { However, Individual A also } \\
\text { sometimes watches news } \\
\text { anchors who support pro-life } \\
\text { policies and reads articles by } \\
\text { authors with these views. }\end{array}$ & $\begin{array}{l}\text { This is because Individual } \\
\text { A wants to find a middle } \\
\text { ground and help end all the } \\
\text { fighting over abortion, even } \\
\text { if that means compromising } \\
\text { with people who support } \\
\text { pro-life policies. }\end{array}$ & $\begin{array}{l}\text { This is because Individual A } \\
\text { hopes to convince those } \\
\text { who support pro-life } \\
\text { policies to change their } \\
\text { minds, and he feels that } \\
\text { learning their arguments } \\
\text { will help him develop } \\
\text { better counterarguments. }\end{array}$ \\
\hline $\begin{array}{c}\text { Perspective } \\
\text { avoider }\end{array}$ & $\begin{array}{l}\text { In addition, Individual A hardly } \\
\text { ever watches news anchors } \\
\text { who support pro-life policies } \\
\text { and reads articles by authors } \\
\text { with these views. }\end{array}$ & $\begin{array}{l}\text { This is because Individual } \\
\text { A wants to stop fighting } \\
\text { over abortion and knows } \\
\text { that hearing from people } \\
\text { with these views would just } \\
\text { make him angry and want } \\
\text { to argue with them. }\end{array}$ & $\begin{array}{l}\text { This is because Individual } \\
\text { A feels deeply committed } \\
\text { to his core principles, and } \\
\text { he strives to remain loyal } \\
\text { and supportive of his } \\
\text { beliefs. }\end{array}$ \\
\hline Baseline & $\begin{array}{l}\text { Individual A also seeks out } \\
\text { non-political entertainment } \\
\text { by watching tv hosts from } \\
\text { other stations and reading } \\
\text { articles by authors who write } \\
\text { about various other topics. }\end{array}$ & $\mathrm{N} / \mathrm{A}$ & N/A \\
\hline
\end{tabular}

with and even cede ground to opponents or to develop counterarguments against them.

\section{Metbod}

Participants. Following our preregistration, we first recruited and analyzed data from 601 American participants from Amazon's Mechanical Turk. We then assessed whether any key tests yielded $p$ values between .050 and .200. If so, our results would be difficult to interpret with certainty, so our preregistration mandated that we would double our sample size. Analyses of the initial sample, reported in the Supplemental Material, indeed yielded $p$ values in that range, so we recruited an additional 602 participants, providing a sample of 1,203 participants. Following our preregistration, we excluded 36 participants who failed an instructional attention check, 140 who failed an English-comprehension check, and nine who self-reported low data quality. These exclusions overlapped, leaving 1,039 participants ( $52 \%$ female, $1 \%$ nonbinary or agender; mean age $=34.38$ years $)$. They tended toward liberalism $(M=3.38, S D=1.63$, significantly below the midpoint of 4$)$, one-sample $t(1038)=$ $-12.26, p<.001$.

Procedure. Following the same procedure as in Study $1 \mathrm{a}$, we asked participants to report their stance on four policy issues-immigration once again as well as three new issues: abortion, universal health care, and gun control. Next, participants read a vignette similar to Study 1a's (but featuring only one copartisan target) in a between-subjects design. The vignette depicted a target who often heard about politics from ideologically consistent sources.

The remainder of the vignette differed across five conditions. One condition served as a baseline, presenting no other politically relevant information. The other four conditions were arranged in a $2 \times 2$ design (see Table 4). We manipulated whether the seeker had cooperative motives (i.e., trying to end conflict with people who hold different beliefs) or competitive motives (i.e., trying to advance their cause through better counterarguments). For the sake of symmetry and to provide reasonable justification for the avoider's behavior, we also manipulated that target's motives: The cooperative avoider wanted to stop fighting and knew that hearing opponents' views would make him angry and argumentative (as in Dorison et al., 2019); the competitive avoider did not want to betray his core principles by fraternizing with the enemy.

Measures. Participants completed the same three dependent measures $(\alpha=.88)$ from Study 1a: feeling thermometer, desired social proximity $(\alpha=.96)$, and emotions toward the target $(\alpha=.91)$. For desired social proximity, we used the four items from Study 1a plus eight additional items (i.e., the full scale from Skitka et al., 2005): "as a neighbor," "to work at the same place I do," "as a 
Table 5. Between-Conditions Comparison of Participants Attitudes in Study 2

\begin{tabular}{lcc}
\hline Condition & $M(S D)$ & $\begin{array}{c}\text { Comparison with } \\
\text { baseline }\end{array}$ \\
\hline Cooperative seeker & $0.24(0.80)$ & $p=.012, d=0.25$ \\
Competitive seeker & $0.20(0.89)$ & $p=.059, d=0.19$ \\
Baseline & $0.04(0.82)$ & - \\
Cooperative avoider & $-0.36(0.98)$ & $p<.001, d=0.44$ \\
Competitive avoider & $-0.13(0.88)$ & $p=.049, d=0.19$ \\
\hline
\end{tabular}

roommate," "to marry into my family," "as someone I would personally date," "as my personal physician," "as the owner of a store or restaurant I frequent," and "as my spiritual advisor."

\section{Results}

We first preregistered analyses replicating the standard preference for seekers. As noted in Table 1, this preference emerged in every study; we therefore report those analyses in the Supplemental Material and proceed directly to the study's novel contribution.

Following our preregistration, we next set aside the baseline condition, testing a 2 (target type: seeker vs. avoider) $\times 2$ (motive: cooperative vs. competitive) between-subjects analysis of variance (ANOVA). This revealed a strong main effect of target type, $F(1,825)=$ 54.64, $p<.001, \eta_{p}{ }^{2}=.063$, qualified by a significant but much smaller interaction, $F(1,825)=4.73, p=.030, \eta_{p}{ }^{2}=$ .006. Participants preferred all seekers to all avoiders ( $p$ s $<.001$ in all cases), but this preference was especially strong when targets had cooperative $(d=0.66)$ rather than competitive $(d=0.37)$ motives (see Table 5). Viewed differently, participants liked both seekers similarly, regardless of their desire to cooperate or compete with opponents, $p=.620, d=0.05$. However, they especially disliked the cooperative avoider, who wanted to prevent conflict with political foes, compared with the competitive avoider, who was motivated by commitment to their favored beliefs, $p=.014, d=0.24$.

Following our preregistration, we next conducted a five-level one-way ANOVA including the baseline condition, $F(4,1033)=15.96, p<.001, \eta_{p}{ }^{2}=.06$; Table 5 displays these comparisons, which support the same conclusions as reported in our meta-analysis above. ${ }^{6}$

\section{Discussion}

People preferred perspective seekers regardless of their motives: Participants liked competitive seekers who promoted partisan goals yet, surprisingly, also liked cooperative seekers who ceded ground to opponents, perhaps because their tolerant, cooperative rationality overshadowed their coziness with abhorrent views.
Seekers' and avoiders' motives vary beyond those used here, though; Study 4 further tested robustness by attributing still different motives.

\section{Study 3}

Our theorizing suggests that people's preference for seekers should weaken when seekers provide comparatively greater validation for opponents' views, thereby seeming more likely to adopt them. Our seekers thus far sought opponents' views but still ultimately endorsed participants', which could be crucial for allaying participants' concerns and blunting their negative reactions. Study 3 (https://osf.io/9dfvp) tested whether people's preferences diminish when seekers lack partisan commitment and validate opponents' views relatively more.

\section{Method}

Participants. We recruited 605 American participants through Amazon's Mechanical Turk. Following our preregistration, we excluded 14 who failed an attention check and 11 who failed an English-comprehension check, leaving 580 participants ( $54 \%$ female; mean age $=37.37$ years) They tended toward liberalism $(M=3.74, S D=1.64$, significantly below the midpoint of 4$), t(579)=-3.82, p<.001$.

Procedure. Participants rated their stance on the same four political issues used in Study 2 before reading a vignette describing a single target, manipulated in a 2 (target: seeker vs, avoider) $\times 3$ (commitment: fully committed vs. partially committed vs. uncommitted) betweensubjects design. Table 6 summarizes each condition (see the preregistered materials for the full text). As in our prior studies, we used the first independent variable to manipulate whether the target sought or avoided views that the participant opposed. For example, a participant who supported increased gun control read about a target who either sought or avoided pro-gun-rights views.

The second independent variable manipulated the target's commitment to views the participant supported. Prior to the manipulation just described, the vignette portrayed the target either as either fully committed to participants' own views (i.e., a copartisan, as in previous studies), partially committed, or uncommitted. Continuing the example above, in the fully committed condition, the participant would read this description:

Individual A supports increased gun control and believes that the government should do more to regulate citizen's firearms. Individual A often hears about gun regulation from the perspective of those who have similar views, such as TV news anchors and authors who argue in favor of increased gun control. 
Table 6. Summary of the Conditions in Study 3

\begin{tabular}{|c|c|c|c|}
\hline \multirow[b]{2}{*}{ Target } & \multicolumn{3}{|c|}{ Target's validation of participants' own views, relative to their opponents' } \\
\hline & Fully committed & Partially committed & Uncommitted \\
\hline $\begin{array}{l}\text { Perspective } \\
\text { seeker }\end{array}$ & $\begin{array}{l}\text { Seeks views I oppose, } \\
\text { supports my side }\end{array}$ & $\begin{array}{l}\text { Undecided, seeks views } \\
\text { I oppose and those I } \\
\text { support }\end{array}$ & $\begin{array}{l}\text { Undecided, seeks } \\
\text { views I oppose }\end{array}$ \\
\hline $\begin{array}{l}\text { Perspective } \\
\text { avoider }\end{array}$ & $\begin{array}{l}\text { Avoids views I } \\
\text { oppose, supports } \\
\text { my side }\end{array}$ & $\begin{array}{l}\text { Undecided, avoids } \\
\text { views I oppose but } \\
\text { seeks those I support }\end{array}$ & $\begin{array}{c}\text { Undecided, avoids } \\
\text { views I oppose }\end{array}$ \\
\hline
\end{tabular}

This description was followed by our standard manipulation of seeking versus avoiding. In the other two conditions, the vignette portrayed the target as increasingly less committed. In both conditions, the target was an undecided voter, described thus:

Individual A is a first-time voter who is undecided about gun regulation and hasn't chosen a stance on this issue yet. Individual A knows that some people have stronger feelings about gun regulation than he does, and that these views are often represented by TV news anchors and authors.

In the partially committed condition, the undecided voter planned to at least seek out views on participants' own side; participants read, "Recently Individual A started intentionally seeking out the perspectives of news anchors and authors who support increased gun control." This was followed by our standard manipulation of seeking versus avoiding. In the uncommitted condition, this wording was omitted: The target never mentioned the views participants supported, and participants read only our standard manipulation, in which the target planned to either seek or avoid views on the opposing side.

Participants then completed the same three dependent measures $(\alpha=.84)$ from Study 2: feeling thermometer, desired social proximity ( $\alpha=.96 ; 12$-item scale), and emotions $(\alpha=.90)$.

We also included exploratory questions asking participants to anticipate targets' future beliefs on this issue. The Supplemental Material reports analyses using these measures, supporting our reasoning that seekers seem liable to adopt opponents' views, leading people to like them less.

\section{Results}

We assessed whether preferences for seekers varied with the target's commitment to participants' views. A $2 \times 3$ between-subjects ANOVA revealed two main effects:
Overall, participants preferred targets who sought rather than avoided views that participants themselves disagreed with, $F(1,574)=21.15, p<.001, \eta_{p}{ }^{2}=.036$, and preferred targets who were more committed to their side, $F(2,574)=10.55, p<.001, \eta_{p}^{2}=.036$ (see Fig. 4). Critically, these effects were qualified by a significant interaction, $F(2,574)=6.15, p=.002, \eta_{p}^{2}=.021$.

We tested the simple effects in each commitment condition (see Fig. 4). As noted earlier, we replicated our usual effect: Participants preferred a fully committed target who sought rather than avoided opposing views, $p<.001, d=0.64$. This preference persisted, although it was slightly weaker, when targets were partially committed to participants' views, $p<.001, d=$ 0.53. In other words, participants still preferred undecided targets who sought their opponents' views over those who avoided them, as long as these targets sought the participants' side as well. However, when the target was uncommitted, participants no longer preferred the seeker, $p=.849, d=-0.03$, rating both targets equally. In other words, participants no longer preferred, but surprisingly still did not dislike, seekers who sought and validated their opponents' views yet failed to acknowledge the participants' own.

\section{Discussion}

Participants' preference for targets who sought their opponents' views weakened when targets were less committed to hearing the participants' own side. Exploratory analyses, described in the Supplemental Material, suggest that this occurred because less committed seekers seemed more likely to adopt participants' opponents' views. This complements Study 1a's findings, supporting our theorizing that people dislike seekers partially because they seem open to changing their mind. Nevertheless, participants still preferred seekers to avoiders unless the seekers completely overlooked observers' own views, which suggests that this preference depends on seekers at least acknowledging both sides. 


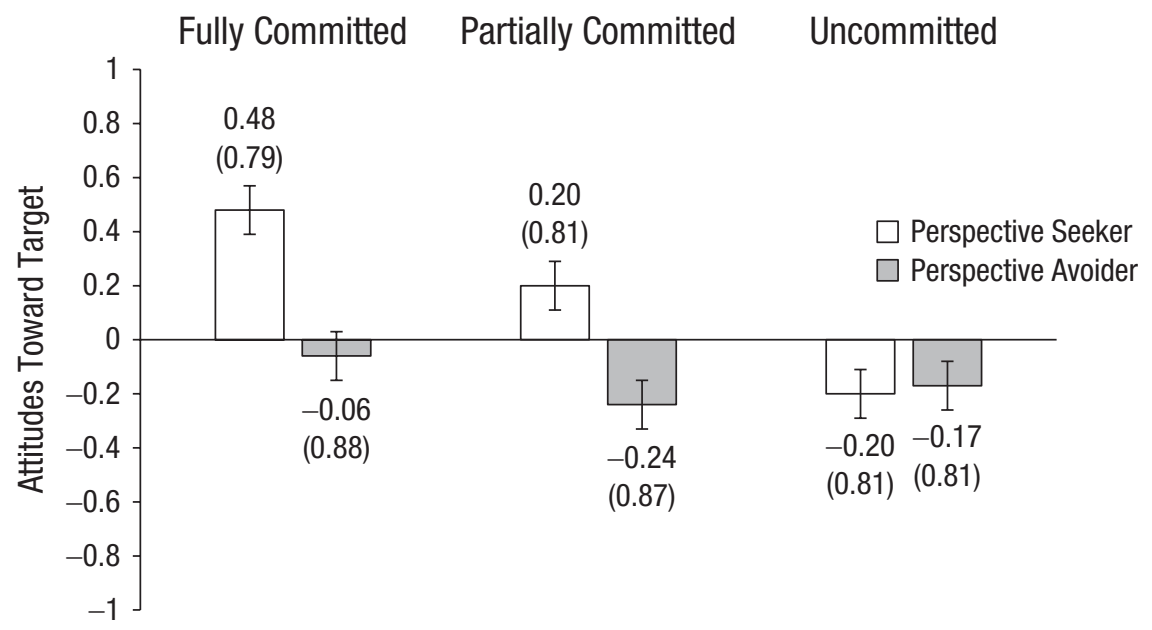

Fig. 4. Mean attitude toward perspective-seeking and perspective-avoiding targets in Study 3 , separately for each of the three commitment conditions. Standard deviations are given in parentheses. Error bars represent standard errors.

\section{Study 4}

Our theorized mechanisms suggest that participants should dislike perspective seekers more to the extent that they seek more illegitimate opposing viewpoints, thereby validating worse views and implying that those views could be right. Study 4 (https://osf.io/wqchx) therefore included copartisan targets who sought to understand extremist opponents, whose views participants presumably find especially illegitimate.

\section{Metbod}

Participants. We recruited 263 American participants through Amazon's Mechanical Turk. Following our preregistration, we excluded six participants who failed an attention check, 26 who failed an English-comprehension check, and six who self-reported low data quality. These exclusions overlapped, leaving 231 participants ( $50 \%$ female, $1 \%$ nonbinary; mean age $=34.53$ years) . They tended toward liberalism $(M=3.57, S D=1.73$, below the midpoint of 4$), t(230)=-3.77, p<.001$.

Procedure. Participants first rated their stance on the same four issues as in Studies 2 and 3. Next, returning to a within-subjects design, we asked participants to read a vignette describing two copartisan targets. We manipulated an additional between-subjects factor: the content of the views in question. In one condition, similar to those in previous studies, the targets sought or avoided standard, broadly framed opposing views. In a second condition, the targets sought or avoided extreme opposing views: For example, rather than reading about targets who seek or avoid the views of pro-choice policy supporters in general, a pro-life participant would read about targets who seek or avoid the views of those who support specific, extreme pro-choice policies, such as allowing abortions far later into a pregnancy than is currently legal anywhere in the United States (participants' home country). Table 7 presents the standard and extreme stances used for all four issues.

We also provided new motives for our targets' behavior. Specifically, the seeker even more clearly validated opponents' views, saying they "are worth considering and deliberating." We made the avoider as well-informed and reasonable as possible, saying he "feels like he already understands why people hold these beliefs and he does not find these reasons convincing." Although any specific motive is subject to many interpretations (e.g., was the cooperative avoider in Study 2 a wise emotion regulator, or did he have a disturbing anger problem he was struggling to keep under control?), by including additional motives in this study (as well as in Studies S9 and S10), we further tested the robustness of our effects across motives.

Participants then responded to the same three dependent measures $(\alpha=.84)$ from Study 1a: feeling thermometer, desired social proximity $(\alpha=.96$; 4-item scale), and emotions $(\alpha=.91)$. They also completed demographic information and attention checks.

Finally, to ensure that participants perceived extreme stances as more illegitimate than standard stances, they rated their agreement with two items, "I question the moral character of people who [support/oppose] . .." and "It's hard to imagine someone having good, valid reasons for [supporting/opposing] ..." using a scale ranging from 1 (strongly disagree) to 7 (strongly agree). Each item depicted the stance (standard vs. extreme) 
Table 7. Wording of Standard and Extreme Stances for Each of the Issues Presented in Study 4

\begin{tabular}{|c|c|c|}
\hline Issue and position & Standard stance & Extreme stance \\
\hline \multicolumn{3}{|l|}{ Abortion } \\
\hline Support & $\begin{array}{l}\text { Support pro-choice } \\
\text { policies }\end{array}$ & $\begin{array}{l}\text { Support extreme pro-choice policies, like allowing abortions for } \\
\text { any reason until the 6th month of pregnancy and for specific } \\
\text { health reasons until the 8th month }\end{array}$ \\
\hline Oppose & Support pro-life policies & $\begin{array}{l}\text { Support extreme pro-life policies, like prohibiting abortion } \\
\text { completely, even in cases of rape and incest }\end{array}$ \\
\hline \multicolumn{3}{|l|}{ Universal healthcare } \\
\hline Support & $\begin{array}{l}\text { Support universal } \\
\text { healthcare policies }\end{array}$ & $\begin{array}{l}\text { Support extreme universal healthcare policies, like the government } \\
\text { fully funding any medical services for U.S. citizens }\end{array}$ \\
\hline Oppose & $\begin{array}{l}\text { Oppose universal } \\
\text { healthcare policies }\end{array}$ & $\begin{array}{l}\text { Oppose even basic government funded healthcare programs, and } \\
\text { support the extreme policy of leaving individual citizens entirely } \\
\text { responsible for paying for their health care needs }\end{array}$ \\
\hline \multicolumn{3}{|l|}{ Gun regulation } \\
\hline Support & $\begin{array}{l}\text { Support increased gun } \\
\text { control }\end{array}$ & $\begin{array}{l}\text { Support extreme increases in gun control policies, like the } \\
\text { government seizing control of citizen's firearms }\end{array}$ \\
\hline Oppose & Support gun rights & $\begin{array}{l}\text { Support extreme gun rights policies, like removing all existing } \\
\text { background checks }\end{array}$ \\
\hline \multicolumn{3}{|l|}{ Immigration } \\
\hline Support & Support tougher policies & $\begin{array}{l}\text { Support extremely tough immigration policies, like creating walls } \\
\text { and flight bans that completely halt immigration from several } \\
\text { countries }\end{array}$ \\
\hline Oppose & Oppose tougher policies & $\begin{array}{l}\text { Oppose even basic limits on immigration, and support the extreme } \\
\text { policy of allowing mass immigration with no restrictions }\end{array}$ \\
\hline
\end{tabular}

Note: Each phrase started with "Both Individual A and Individual B" and was followed by one of the standard or extreme stances shown.

participants had seen in the vignette earlier. We averaged responses to index perceived illegitimacy $(\alpha=$ .89). In Studies 2 and 3, exploratory analyses using these items (reported in the Supplemental Material) supported our theorizing: Participants who found their opponents' views more illegitimate showed a diminished preference for seekers.

\section{Results}

Manipulation check. As expected, participants found extreme stances more illegitimate $(M=5.29, S D=1.38)$ than standard ones $(M=4.09, S D=1.70), t(439)=8.34, p<.001$.

Role of viewpoint extremity. A multilevel linear model predicting attitudes from target type (seeker coded 1, avoider coded 0 ), view extremity (extreme coded 1 , standard coded 0 ), their interaction, and random intercepts for participant and vignette issue revealed a significant interaction, $b=-0.40, S E=0.155,95 \% \mathrm{CI}=[-0.71,-0.10]$, $t(456)=-2.62, p=.009$. Effects differed in the extremeviews condition, but this difference was only a matter of size: Simple-slopes tests revealed that participants still preferred seekers of extreme opposing views over avoiders, $b=0.27, S E=0.118,95 \%$ CI $=[0.04,0.50], t(228)=2.28$, $p=.023, d=0.30$, though this preference was less than half that observed for standard opposing views, $b=0.67, S E=0.100,95 \% \mathrm{CI}=[0.48,0.87], t(230)=6.73$, $p<.001, d=0.88$ (see Fig. 5). Moreover, by replicating this preference using still different motives, these results further suggest that this preference is not contingent on any particular motive.

Viewed differently, participants disliked avoiders regardless of whether they avoided standard or extreme views, $b=0.05, S E=0.116,95 \% \mathrm{CI}=[-0.17,0.28]$, $t(229)=0.47, p=.641, d=0.06$. They liked seekers less, however, when they sought extreme rather than standard views, $b=-0.35, S E=0.102,95 \% \mathrm{CI}=[-0.55$, $-0.15], t(229)=3.44, p=.001, d=-0.45$. This is consistent with our theorizing, as seekers who validated especially illegitimate views elicited less liking. Yet participants still preferred these seekers over avoiders, showing the strength of this preference. For a concrete example, consider pro-life participants in our study: Despite deep, morally charged disagreement about abortion (Parker \& Janoff-Bulman, 2013), these participants preferred a fellow pro-lifer who sought to better understand supporters of very-late-term abortions over one who already understood these supporters' arguments and therefore avoided them. 


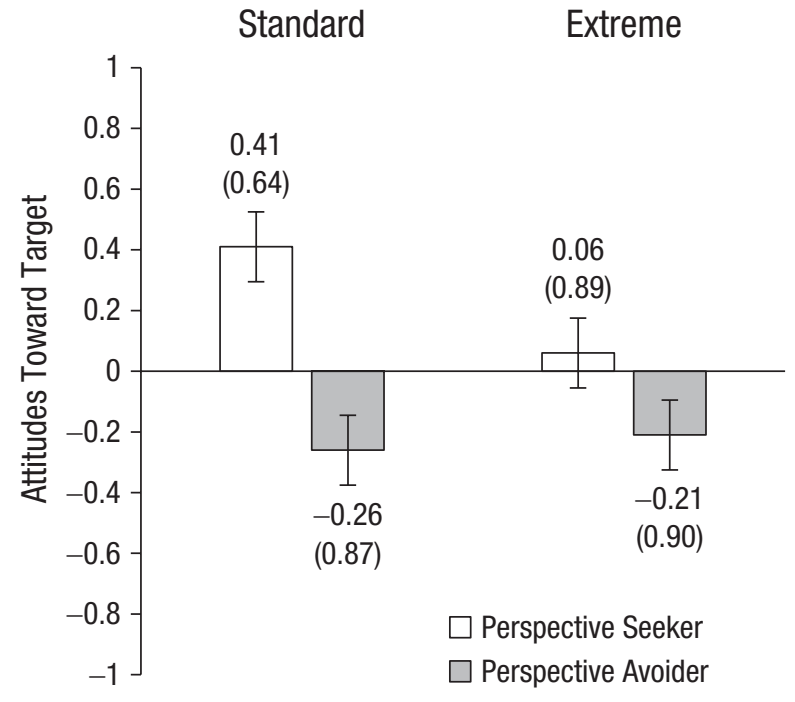

Fig. 5. Mean attitude toward targets in Study 4, separately for each extremity condition. Standard deviations are given in parentheses. Error bars represent standard errors.

\section{Discussion}

Although people resent extreme opponents (Feinberg et al., 2020), participants still preferred targets who sought rather than avoided extreme perspectives. And yet this preference was much weaker, compared with their liking for seekers of more moderate, less illegitimate views. Studies 2 and 3 conceptually replicated this using an exploratory measure of perceived illegitimacy (see the Supplemental Material). These convergent findings bolster our claim that concerns about validating illegitimate views suppress the preference for seekers.

\section{General Discussion}

People generally like political allies who seek to understand, rather than avoid, shared opponents' beliefs. These findings suggest that Sarah Silverman's show might have been canceled despite her willingness to hear opposing views, not because of it. More importantly, they align with recent evidence that people prefer copartisans who tolerate and respect their opponents (Druckman et al., 2019; Frimer \& Skitka, 2018; see Heltzel \& Laurin, 2020). Yet they clash with other work suggesting that people do not tolerate their political opponents (Haidt et al., 2003), dislike copartisan politicians who compromise with opponents (Ryan, 2017), and reject people who empathize with proponents of illegitimate views (Wang \& Todd, 2020).

Our findings reframe this contradiction, suggesting that both tendencies coexist: Seekers are both admirable and alarming but to different degrees. People like them because they seem tolerant, cooperative, and rational, yet they simultaneously (and to a lesser degree) dislike them for validating illegitimate beliefs and potentially changing their minds. Accordingly, people like seekers less when they lack partisan commitments and seek especially illegitimate viewpoints.

\section{Theoretical implications}

Our findings contribute to a new literature extending political intolerance from its intergroup origins to intragroup contexts. In so doing, we highlight a paradox: People refuse to tolerate political out-groups (Finkel et al., 2020; Haidt et al., 2003; Kalmoe \& Mason, 2019), yet value tolerance and praise tolerant in-group members (W. Brown, 2009; Druckman et al., 2019; Frimer \& Skitka, 2018), even those willing to compromise with the enemy (Study 2). However, people do not praise in-group leaders who could actually enact compromise (Ryan, 2017). More research is needed to understand these contours of people's political tolerances (and intolerances) and how people reconcile their paradoxical reactions in their own minds (Guan et al., in press).

Our findings also speak to ongoing debates about whether conservatives, extremists, or moralizers are most guilty of political intolerance (Crawford, 2014; Ganzach \& Schul, 2021; Skitka, 2010). Our findings best support the intolerant-extremist view, while also highlighting commonalities across levels of ideology and moralization.

\section{When might people prefer avoiders?}

Despite focusing on contentious, morally laden issues (e.g., abortion, gun control, immigration; Koleva et al., 2012), we never observed a case in which participants preferred avoiders over seekers. Our mechanisms nonetheless allow for such cases. For example, our participants were North Americans, but other societies value tolerance and rationality less and therefore might like seekers less. Additionally, there should be a point at which beliefs seem so illegitimate that people prefer others who avoid rather than seek them. Perhaps the beliefs featured in our studies never reached this point: Even the extreme views from Study 4 were rated far from maximally illegitimate (5.29 on a 7-point scale).

That said, many people expect their political opponents to hold precisely these sorts of abhorrent views (Ahler \& Sood, 2018). When perspective seekers aim to understand their opponents in general, their allies' minds may naturally conjure the worst of these opponents' views and take great offense. For instance, liberals may interpret copartisans' seeking to understand conservatives as trying to understand White supremacists, and conservatives may interpret copartisans' seeking to 
understand liberals as trying to understand flag-burning Communists. For this reason, seekers might be most liked when seeking opponents' views on specific policy debates. Indeed, Studies 1b and S7 revealed a remarkably weaker preference for targets who sought to understand their ideological opponents generally rather than their specific policy beliefs (see Table 1).

\section{Intuitions about perspective seeking's social desirability}

For many-ourselves included-these findings may seem counterintuitive. Outrage pervades political discourse on social media and in the news (Brady et al., 2020; Pew Research Center, 2019), fueling intuitions that people's hate for opponents would extend to allies seeking those opponents' views. Our results suggest that this intuition is incorrect, but even incorrect intuitions can powerfully shape behavior (Prentice \& Miller, 1993). For instance, if people mistakenly believe that others discourage political-perspective seeking, they may abstain from it out of fear of social punishment, thereby perpetuating polarization.

\section{Transparency}

Action Editor: Mark Brandt

Editor: Patricia J. Bauer

Author Contributions

G. Heltzel developed the study concept under the supervision of K. Laurin. Both of the authors contributed to the study design. Testing and data collection were performed by G. Heltzel. G. Heltzel analyzed and interpreted the data under the supervision of K. Laurin. G. Heltzel drafted the manuscript, and K. Laurin provided critical revisions. Both of the authors approved the final version of the manuscript for submission.

Declaration of Conflicting Interests

The author(s) declared that there were no conflicts of interest with respect to the authorship or the publication of this article.

Open Practices

All data and materials have been made publicly available via OSF and can be accessed at https://osf.io/3zwxc/ and https://osf.io/uksdf/, respectively. The design and analysis plans for all of the studies reported in the main text were preregistered (Study 1a: https://osf.io/mjt7u, Study 1b: https://osf.io/6s8gc, Study 1c: https://osf.io/hnb5s, Study 2: https://osf.io/dvbhu, Study 3: https://osf.io/9dfvp, Study 4: https://osf.io/wqchx). This article has received the badges for Open Data, Open Materials, and Preregistration. More information about the Open Practices badges can be found at http://www.psychologicalscience.org/publica tions/badges.

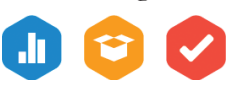

\section{ORCID iD}

Gordon Heltzel (iD https://orcid.org/0000-0003-4632-6981

\section{Supplemental Material}

Additional supporting information can be found at http:// journals.sagepub.com/doi/suppl/10.1177/09567976211011969

\section{Notes}

1. Participants in Study 1a showed the strongest liberal tendency in all our studies.

2. All studies additionally measured ideological orientation and extremity; we describe results for these variables in the internal meta-analysis. All studies also included additional measures for which we preregistered neither predictions nor analyses; these are available in the preregistered materials and data.

3. Testing for moderation by ideological variables in this and all studies revealed small interactions that were only occasionally significant. We therefore report these study-level analyses in the Supplemental Material, and after Study 1c, we report an internal meta-analysis across all data points to more precisely test these moderations and compare them against the backdrop of the larger, more consistent preference for seekers.

4. Our preregistration stated our intention to exclude participants who rated the baseline target using either scale end point ( $n=9$ ) because these participants' responses to the critical conditions could shift only one way (e.g., rating the baseline target 100 meant the seeker and avoider targets could be rated equally or more negatively but not more positively). Results are stronger if we follow this plan (see the Supplemental Material for detailed analyses), but in retrospect, we found that our justification for this exclusion was weak, and these responses could be meaningful. For that reason, we include them here.

5. This study also preregistered a test of some outdated theorizing regarding the mechanisms underlying participants' attitudes: We asked participants to rate each target's warmth and competence, predicting that perceived warmth would play a mediating role. For the rationale for these measures, their wording, the results (aligning with our predictions), and the reason why we ultimately adopted more precise theorizing about mechanisms, see the Supplemental Material.

6. Because we checked our results before collecting the full sample, best statistical practices suggest that we correct our threshold for significance (Lakens, 2014). The Pocock method suggests we use .028 as a threshold, the O'Brien-Fleming method suggests .049, and the Power Family method suggests .034 . Readers can evaluate the reported $p$ values against whichever of these they find appropriate.

\section{References}

Abramowitz, A. I., \& Webster, S. W. (2018). Negative partisanship: Why Americans dislike parties but behave like rabid partisans. Political Psychology, 39, 119-135. https://doi .org/10.1111/pops.12479

Ahler, D. J., \& Sood, G. (2018). The parties in our heads: Misperceptions about party composition and their 
consequences. The Journal of Politics, 80, 964-981. https://doi.org/10.1086/697253

Brady, W. J., Crockett, M. J., \& Van Bavel, J. J. (2020). The MAD model of moral contagion: The role of motivation, attention, and design in the spread of moralized content online. Perspectives on Psychological Science, 15(4), 978-1010. https://doi.org/10.1177/1745691620917336

Brown, P., \& Levinson, S. C. (1987). Politeness: Some universals in language usage. Cambridge University Press.

Brown, W. (2009). Regulating aversion: Tolerance in the age of identity and empire. Princeton University Press.

Chmielewski, M., \& Kucker, S. C. (2020). An MTurk crisis? Shifts in data quality and the impact on study results. Social Psychological and Personality Science, 11, 464-473. https://doi.org/10.1177/1948550619875149

Cohen, P., Cohen, J., Aiken, L. S., \& West, S. G. (1999). The problem of units and the circumstance for POMP. Multivariate Behavioral Research, 34, 315-346.

Crawford, J. T. (2014). Ideological symmetries and asymmetries in political intolerance and prejudice toward political activist groups. Journal of Experimental Social Psychology, 55, 284-298. https://doi.org/10.1016/j.jesp .2014 .08 .002

Dorison, C. A., Minson, J. A., \& Rogers, T. (2019). Selective exposure partly relies on faulty affective forecasts. Cognition, 188, 98-107. https://doi.org/10.1016/j.cogni tion.2019.02.010

Druckman, J. N., Gubitz, S. R., Levendusky, M. S., \& Lloyd, A. M. (2019). How incivility on partisan media (de)polarizes the electorate. The Journal of Politics, 81, 291-295. https://doi.org/10.1086/699912

Fehr, E., \& Fischbacher, U. (2004). Social norms and human cooperation. Trends in Cognitive Sciences, 8, 185-190. https://doi.org/10.1016/j.tics.2004.02.007

Feinberg, M., Willer, R., \& Kovacheff, C. (2020). The activist's dilemma: Extreme protest actions reduce popular support for social movements. Journal of Personality and Social Psychology, 119(5), 1086-1111. https://doi.org/10.1037/ pspi0000230

Finkel, E. J., Bail, C. A., Cikara, M., Ditto, P. H., Iyengar, S., Klar, S., Mason, L., McGrath, M. C., Nyhan, B., Rand, D. G., Skitka, L. J., Tucker, J. A., Van Bavel, J. J., Wang, C. S., \& Druckman, J. N. (2020). Political sectarianism in America. Science, 370(6516), 533-536. https://doi.org/10 $.1126 /$ science.abe 1715

Fiske, S. T., Cuddy, A. J., \& Glick, P. (2007). Universal dimensions of social cognition: Warmth and competence. Trends in Cognitive Sciences, 11, 77-83.

Frimer, J. A., \& Skitka, L. J. (2018). The Montagu principle: Incivility decreases politicians' public approval, even with their political base. Journal of Personality and Social Psychology, 115, 845-866. https://doi.org/10.1037/ pspi0000140

Frimer, J. A., Skitka, L. J., \& Motyl, M. (2017). Liberals and conservatives are similarly motivated to avoid exposure to one another's opinions. Journal of Experimental Social Psychology, 72, 1-12. https://doi.org/10.1016/j .jesp.2017.04.003
Galinsky, A. D., Ku, G., \& Wang, C. S. (2005). Perspectivetaking and self-other overlap: Fostering social bonds and facilitating social coordination. Group Processes and Intergroup Relations, 8, 109-124. https://doi.org/ $10.1177 / 1368430205051060$

Ganzach, Y., \& Schul, Y. (2021). Partisan ideological attitudes: Liberals are tolerant; the intelligent are intolerant. Journal of Personality and Social Psychology, 120(6), 1551-1566. https://doi.org/10.1037/pspi0000324

Golman, R., Hagmann, D., \& Loewenstein, G. (2017). Information avoidance. Journal of Economic Literature, 55, 96-135. https://doi.org/10.1257/jel.20151245

Guan, K., Heltzel, G., \& Laurin, K. (in press). Morality and politics. In P. A. Robbins \& B. F. Malle (Eds.), Cambridge handbook of moral psychology. Cambridge University Press.

Haidt, J., Rosenberg, E., \& Hom, H. (2003). Differentiating diversities: Moral diversity is not like other kinds. Journal of Applied Social Psychology, 33, 1-36. https://doi.org/ 10.1111/j.1559-1816.2003.tb02071.x

Heltzel, G., \& Laurin, K. (2020). Polarization in America: Two possible futures. Current Opinion in Behavioral Sciences, 34, 1689-1699. https://doi.org/10.1017/CBO 9781107415324.004

Iyengar, S., Lelkes, Y., Levendusky, M., Malhotra, N., \& Westwood, S. J. (2019). The origins and consequences of affective polarization in the United States. Annual Review of Political Science, 22, 129-146. https://doi.org/10.1146/ annurev-polisci-051117-073034

Kalmoe, N. P., \& Mason, L. (2019, January). Lethal mass partisanship: Prevalence, correlates, \& electoral contingencies [Conference session]. National Capital Area Political Science Association American Politics Meeting, Washington, DC, United States.

Koleva, S. P., Graham, J., Iyer, R., Ditto, P. H., \& Haidt, J. (2012). Tracing the threads: How five moral concerns (especially purity) help explain culture war attitudes. Journal of Research in Personality, 46, 184-194. https:// doi.org/10.1016/j.jrp.2012.01.006

Lakens, D. (2014). Performing high-powered studies efficiently with sequential analyses. European Journal of Social Psychology, 44(7), 701-710. https://doi.org/10.1002/ ejsp. 2023

Liberman, N., \& Trope, Y. (2008). The psychology of transcending the here and now. Science, 322, 1201-1205. https://doi.org/10.1126/science.1161958

McCoy, J., Rahman, T., \& Somer, M. (2018). Polarization and the global crisis of democracy: Common patterns, dynamics, and pernicious consequences for democratic polities. American Behavioral Scientist, 62, 16-42. https:// doi.org/10.1177/0002764218759576

Mutz, D. C. (2002). Cross-cutting social networks: Testing democratic theory in practice. The American Political Science Review, 96, 111-126.

Norenzayan, A., Smith, E. E., Kim, B. J., \& Nisbett, R. E. (2002). Cultural preferences for formal versus intuitive reasoning. Cognitive Science, 26(5), 653-684. https://doi .org/10.1016/S0364-0213(02)00082-4 
Parker, M. T., \& Janoff-Bulman, R. (2013). Lessons from morality-based social identity: The power of outgroup "hate," not just ingroup "love." Social Justice Research, 26(1), 81-96.

Pennycook, G., McPhetres, J., Bago, B., \& Rand, D. G. (2021). Belief about COVID-19 in Canada, the U.K., and the U.S.A.: A novel test of political polarization and motivated reasoning. PsyArXiv. https://doi.org/10.31234/osf.io/zhjkp

Pew Research Center. (2019, October 10). Partisan antipathy: More intense, more personal. https://www.pewresearch .org/politics/2019/10/10/partisan-antipathy-more-intensemore-personal/

Pierce, J. R., Kilduff, G. J., Galinsky, A. D., \& Sivanathan, N. (2013). From glue to gasoline: How competition turns perspective takers unethical. Psychological Science, 24, 1986-1994. https://doi.org/10.1177/0956797613482144

Prentice, D. A., \& Miller, D. T. (1993). Pluralistic ignorance and alcohol use on campus: Some consequences of misperceiving the social norm. Journal of Personality and Social Psychology, 64, 243-256.

Rosseel, Y. (2012). lavaan: An R Package for structural equation modeling. Journal of Statistical Software, 48(2). https://doi.org/10.18637/jss.v048.i02

RStudio Team. (2019). RStudio: Integrated development for $R$ (Version 1.2.5001) [Computer software]. http://www .rstudio.com/
Ryan, T. J. (2017). No compromise: Political consequences of moralized attitudes. American Journal of Political Science, 61, 409-423. https://doi.org/10.1111/ajps.12248

Schwalbe, M. C., Cohen, G. L., \& Ross, L. D. (2020). The objectivity illusion and voter polarization in the 2016 presidential election. Proceedings of the National Academy of Sciences, USA, 117, 21218-21229. https:// doi.org/10.1073/pnas.1912301117

Shi, F., Teplitskiy, M., Duede, E., \& Evans, J. A. (2019). The wisdom of polarized crowds. Nature Human Behaviour, 3, 329-336. https://doi.org/10.1038/s41562-019-0541-6

Skitka, L. J. (2010). The psychology of moral conviction. Social and Personality Psychology Compass, 4, 267-281.

Skitka, L. J., Bauman, C. W., \& Sargis, E. G. (2005). Moral conviction: Another contributor to attitude strength or something more? Journal of Personality and Social Psychology, 88, 895-917. https://doi.org/10.1037/0022-3514.88.6.895

Ståhl, T., Zaal, M. P., \& Skitka, L. J. (2016). Moralized rationality: Relying on logic and evidence in the formation and evaluation of belief can be seen as a moral issue. PLOS ONE, 11(11), Article e0166332. https://doi.org/10.1371/ journal.pone.0166332

Wang, Y. A., \& Todd, A. R. (2020). Evaluations of empathizers depend on the target of empathy. Journal of Personality and Social Psychology. Advance online publication. https://doi.org/10.1037/pspi0000341 